\title{
COVID-19: perspectivas en bioseguridad odontológica
}

\author{
COVID-19: perspectives in dental biosafety \\ Juana Delgadillo Avila ${ }^{1 a, b}$
}

\section{Sr. Editor}

En el área del trabajo odontológico diversos estudios demuestran que los virus de trasmisión respiratorios se dan por contacto interpersonal directa e indirecto. La mecánica: vía los fluidos en forma de micro o macro gotas intraorales( tos, estornudos y gotas de Flügge) ${ }^{(1)}$ o extraorales (por instrumentos de rotación que generan aerosoles).

La distancia de trabajo del odontólogo a la boca del paciente (menos de $30 \mathrm{~cm}$ ) condiciona a una contaminación cruzada por salpicaduras, aerosol y otros fluidos ${ }^{(2)}$, que ocurren durante el procedimiento. Esto lo expone a contaminarse frecuentemente sea por COVID-19 u otras enfermedades infectocontagiosa, sino se siguen estrictamente las normas de bioseguridad o por un deficiente manejo de ellas ${ }^{(3)}$.

La higiene y lavado de manos exhaustivo será el primer Reductor de la trasmisión por contacto oro-facial que han sido descritos como vías frecuentes de propagación del virus ${ }^{(4)}$. Las superficies de trabajo y el entorno del paciente deben ser limpiados y desinfectados permanentemente, pues estos virus se inactivan a los 5 minutos de exposición a solventes como la lejía doméstica.

El protocolo indica que para admitir un paciente a consulta será evaluado previamente (control de temperatura) y no realizar tratamiento en pacientes sospechosos de ser portadores de COVID-19. Sólo se tratará casos de suma urgencia, previos enguajes bucales que contengan elementos oxidativos tales como el peróxido de hidrógeno al $1 \%$ o povidona yodada al $0,2 \%$; ya que el virus también es vulnerable a la oxidación.

La presencia del COVID-19, debe llevarnos a reforzar todo lo actuado en prevención y protección del profesional y paciente. Siguiendo nuevos protocolos de atención que incluye el uso de equipo de protección personal, mascarillas FFP2 valvuladas o los N95 quirúrgicas ${ }^{(5)}$, máscaras, gafas, pantalla facial, guantes de nitrilo, gorras y batas quirúrgicas desechables.

Universidad Nacional Mayor de San Marcos, Facultad de Odontologia. Lima, Perú

a Doctor en Ciencias de la salud.

${ }^{\mathrm{b}}$ Cirujano Dentista
Este es un artículo Open Access distribuido bajo la licencia Creative Commons Atrucion-NoComercial Compartir igual 4.0

\section{Correspondencia:}

Juana Delgadillo

Correo electrónico: jdelgadilloa@unmsm.edu.pe

Av. Universitaria/ calle Germán Amézaga 375, Ciudad Universitaria, Lima, Perú.

Citar como: Delgadillo Avila J. COVID-19: Perspectivas en bioseguridad odontológica. KIRU. 2020;17(3):175176. https://doi.org/10.24265/kiru.2020.v17n3.09 
Admitámoslo entonces, que la presencia del COVID19 nos sitúa entre los profesionales de la salud, en el grupo de alto riesgo de exposición y contaminación.

Esto nos obliga a respetar rigurosamente la cadena de asepsia y desinfección, antes, durante y después de los procedimientos odontológicos. A implementar cambios estructurales, socioculturales y sanitarios en la metodología de nuestro trabajo profesional presente y futuro.

Conflictos de interés. Los autores no declararon tener conflictos de enteres en esta publicación.

\section{REFERENCIAS}

1. To KK-W, Tsang OT-Y, Yip CC-Y, Chan K-H, Wu $\mathrm{T}-\mathrm{C}$, Chan JM-C, et al. Consistent Detection of 2019 Novel Coronavirus in Saliva. Clin Infect Dis. 12 de febrero de 2020; ciaa149.
2. Watanabe A, Tamaki N, Yokota K, Matsuyama M, Kokeguchi S. Use of ATP bioluminescence to survey the spread of aerosol and splatter during dental treatments. J Hosp Infect. 2018; 99(3):303305.

3. Jiménez González S, Salgado Izquierdo M. Conocimientos y prácticas del personal estomatológico sobre la prevención de enfermedades transmisibles. Marianao. 20152016. Rev Habanera Cienc Médicas. 2017; 16(5):808-821.

4. Meng L, Hua F, Bian Z. Coronavirus Disease 2019 (COVID-19): Emerging and Future Challenges for Dental and Oral Medicine. J Dent Res [Internet]. 12 de marzo de 2020 [citado 26 de abril de 2020]; Disponible en: https://www.ncbi.nlm.nih.gov/pmc/articles/PMC714 0973/

5. Peng X, Xu X, Li Y, Cheng L, Zhou X, Ren B. Transmission routes of 2019-nCoV and controls in dental practice. Int J Oral Sci. 1 de marzo de 2020; 12:9. 